\title{
Peertechz
}

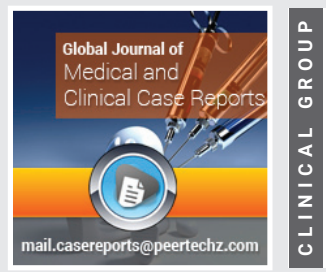

\section{Congenital esophageal stenosis with tracheoesophageal window}

\author{
D’Alessandro Pablo D*, Reusmann Aixa, Rubio Martin A, \\ Cocciaglia Alejandro and Boglione Mariano $\mathrm{M}$ \\ Pediatric Surgeon, Juan Pedro Garrahan National Pediatric Hospital, Buenos Aires, Argentina
}

Received: 13 April, 2020

Accepted: 24 April, 2020

Published: 25 April, 2020

*Corresponding author: D’Alessandro Pablo D, Pediatric Surgeon, Juan Pedro Garrahan National Pediatric Hospital, Buenos Aires, Argentina,

E-mail: dalessandro_pablo@yahoo.com.ar

https://www.peertechz.com

Check for updates

\begin{abstract}
There are different types of congenital anomalies who have its origin in the embryological development of the esophagus and trachea at the fifth and seventh weeks. Examples of these are Laryngotracheoesophageal clefts, esophageal atresia with or without fistula and Congenital Esophageal Stenosis (CES) [1-3].
\end{abstract}

The following case expose a 28-days-old baby boy with a extrange type of tracheoesophageal fistula with an esophageal estenosis.

\section{Case report}

A 28-days-old, 41 week gestation and 3170-g baby boy was admitted on March 22, 2015 with the clinical suspect of esophageal atresia with tracheoesophagical fistula. His fenotipical appearance seems like a genetic síndrome. In a chest $\mathrm{x}$-ray we found that the oragastric catheter reach the rigth brochus, in many attemps to progress it to the stomach we failed. A radiopaque solution througth the tube shown constrast in the airway with a narrow passage to distal esophagus (Figure 1). A superior airway endoscopy was made to seek up a fistula: We observed a big communication between trachea and esophagus at the level of the fifth tracheal cartilague progressing endoscope to carina; in an attemp to reach up the esophagus an stenosis was found above this big communication (Figure 2).

An anterior cervical transverse incision was made. A common space between posterior wall of trachea and anterior wall of the esophagus was visible (Figure 3). Tracheoesophageal communication and esophageal stenosis were resected and trachea and esophagus were anastomosed separately in a terminal way. Previously we introduce a transanastomotic tube throught esophagus for postoperatory early feeding.

The posoperative esophagogram shown no leaks or strictures. Patient starts oral feeding with excelent tolerance.

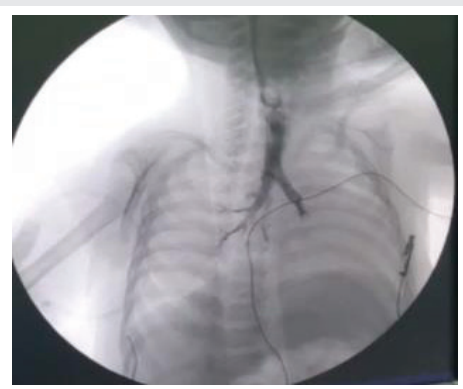

Figure 1: Digital Esophagus.
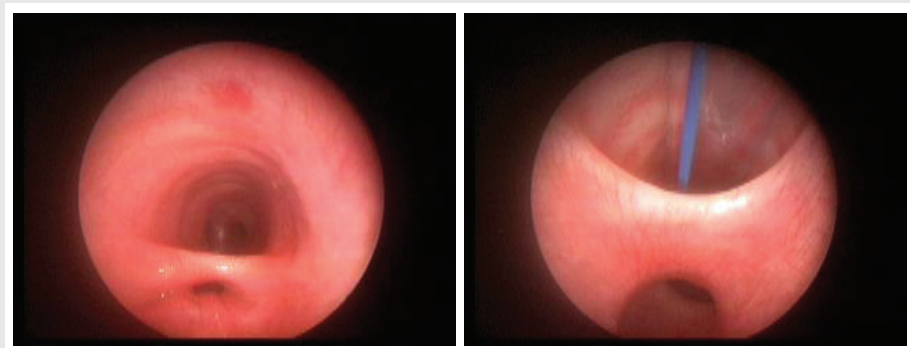

Figure 2A,B: Esophagus Stenosis.

\section{Discusion}

There are different types of congenital anomalies who have 


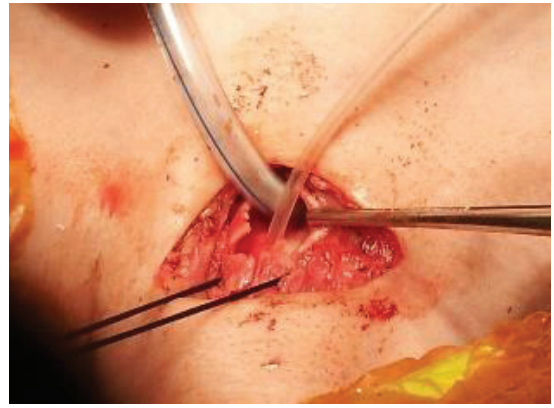

Figure 3: Esophagus Visible.

its origin in the embryological development of the esophagus and trachea. Examples of these are Laryngotracheoesophageal clefts, esophageal atresia with or without fistula and congenital esophageal stenosis.

Herein we describe a twenty-eight days newborn who present difficulties to pass throught an orogastric tube. At the chest $\mathrm{x}$-ray we found that the tube was in the right bronchus. Barium esophagogram shows a perfect tracheogram with a narrowing course to distal esophagus without reaching the stomach.

In the surgery we found a big communication between the trachea and the esophagus that share the posterior wall of the airway and the anterior wall of the digestive tube; above that the normal esophagus had a stenosis imposible to pass throught with a $6 \mathrm{fr}$ catheter.

Since 1973, Spitz was the first to demonstrate a congenital basis for distal esophageal stenosis associated with esophageal atresia by showing the presence of tracheobronchial rest in a esophagectomy specimen $[4,5]$.

In 1987, Nihoul-Fékété et al [4,6] analyse 20 cases of CES and found 2 patients with associated esophageal atresia or tracheoesophageal fistula and define congenital esophageal stenosis as an intrinsic stenosis present at birth, which is caused by a congenital malformation of the esophageal wall not necessarily syntomatic. They classify the etiology as: tracheobronchial rest, membranous diaphragm or segmental hypertrophy of the muscularis and diffuse fibrosis of submucosa.

Analysing and comparing our patient with the previous, we found sustancial differences: our patient has a short round stenosis above the tracheoesophageal fistula that was visible in the surgical procedure because the impossibility to reach the distal esophagus; in those reports, the patients presents as a esophageal atresia with or without fistula and in most cases the stenosis was a postoperative discovery. The esophageal stenosis in these cases present frecuently as a long narrowing segment distal the esophageal anastomosis.

In an attemp to found similar cases to compare and understand our patient, literature offers to us an entity call laryngotracheoeshopageal clefts. Bruce Benjamin and
Andrew Inglis $[7,8]$, in 1989 , classificated this congenital malformation in four types: (I) supraglottic interarytenoid cleft (above the vocal cords); (II) Partial cricoid cleft; (III) Total cricoid cleft (with or without further extension into part of the cervical cervical tracheoesophageal wall) and (IV) Laryngotracheoesophageal cleft (involves major part of the intrathoracic tracheoesophageal wall). In the latest type, if the extension of the cleft rises the carina leaves a common esophageal and tracheal lumen.

Analysing the case once more time, we found only one simmilarity to the Benjamin-Inglis Classification. Our patient had a tracheoesophageal communication like a type IV cleft, but in the endoscopy the supraglotic portion of the larynx and cricoid cartilage were intact and the tracheoesophageal comunication was below tyroid cartilage. If we reach and association between a typical cleft and this case, we are able to think a board spectrum of the previous classification.

Finally, in 1976, Dietrich Kluth [9] describe different types of esophageal atresia. In this atlas, Type IV are call Membranuos Atresias. Looking at the pictures we can compare our finding to the author description.

\section{Conclusion}

Tracheoesophageal fistula has his origin at the fifth to seventh embrionyc weeks in a failure of the fusion of the tracheoesophageal septum. It is clear that the congenital malformation of our patient start at this point of the embryological development.

Intheliteraturewefound differentcases of tracheoesophageal fistula, laryngotracheoesophageal cleft and isolated esophageal stenosis but we did not found similarities to this baby boy. He has a kind of defect that is diferent to the classical reports. We call it esophageal stenosis with "tracheoesophageal window" because the length of the communication (seven tracheal cartilages) no appears to be a classic tracheoesophageal fistula and the integrity of the upper portion of the tracheoesophageal wall rules out a laryngotracheoeshopageal cleft.

\section{References}

1. Spitz L (1993) Pediatric surgery. 2nd ed. K. W. Ashcraft and T. M. Holder (eds). $286 \times 220$ mm. Pp. 1062. Illustrated. 1992. Philadelphia, Pennsylvania: W. B. Saunders. US\$170. Saunders 80: 1084-1084. Link: https://bit.ly/3eWLSU2

2. Fraga JC, Adil EA, Kacprowicz A, Skinner ML, Jennings R, et al. (2015) The association between laryngeal cleft and tracheoesophageal fistula: myth or reality? Laryngoscope 125: 469-474. Link: https://bit.ly/3bLG5Pf

3. Slater BJ, Rothenberg SS (2016) Tracheoesophageal fistula. Semin Pediatr Surg 25: 176-178. Link: https://bit.ly/2VN7k4Q

4. Kawahara $\mathrm{H}$ (2001) Clinical characteristics of congenital esophageal stenosis distal to associated esophageal atresia. Surgery January 129: 29-38. Link: https://bit.ly/3bBFtv8

5. Spitz L (1973) Congenital Esophageal Stenosis Distal to Associated Esophageal Atresia. Journal of Pediatric Surgery 8: 973-974. Link: https://bit.ly/3cG2nS 
6. Nihoul-Fékété C, De Backer A, Lortat-Jacob S (1987) Congenital esophageal stenosis: A review of 20 cases. Pediatr Surg Int 2: 86-92,1987. Link: https://bit.ly/3eFZFhs

7. Benjamin B, Inglis A (1989) Minor congenital laryngeal clefts: diagnosis and classi- fication. Ann Otol Rhinol Laryngol 98: 417-420. Link: https://bit.ly/2VBegU6
8. Strychowsky JE (2016) Laryngotracheoesophageal clefts. Seminars in Pediatric Surgery 25: 128-131. Link: https://bit.ly/3bzSVjl

9. Dietrich Kluth (1976) Atlas of Esophageal Atresia Journal of Pediatric Surgery 11. 901-919. Link: https://go.aws/3eNVtwg

\section{Discover a bigger Impact and Visibility of your article publication with}

\section{Peertechz Publications}

\section{Highlights}

* Signatory publisher of ORCID

* Signatory Publisher of DORA (San Francisco Declaration on Research Assessment)

- Articles archived in worlds' renowned service providers such as Portico, CNKI, AGRIS, TDNet, Base (Bielefeld University Library), CrossRef, Scilit, J-Gate etc.

* Journals indexed in ICMJE, SHERPA/ROMEO, Google Scholar etc.

- OAI-PMH (Open Archives Initiative Protocol for Metadata Harvesting)

* Dedicated Editorial Board for every journal

* Accurate and rapid peer-review process

* Increased citations of published articles through promotions

* Reduced timeline for article publication

Submit your articles and experience a new surge in publication services (https://www.peertechz.com/submission).

Peertechz journals wishes everlasting success in your every endeavours.

Copyright: ( $\odot 2020$ D'Alessandro Pablo D, et al. This is an open-access article distributed under the terms of the Creative Commons Attribution License, which permits unrestricted use, distribution, and reproduction in any medium, provided the original author and source are credited.

Citation: D’Alessandro Pablo D, Aixa R, Rubio Martin A, Alejandro C, Boglione Mariano M (2020) Meaning of writing case report: Revisit. Glob J Medical Clin Case Rep 7(1): 012-014. DOI: https://dx.doi.org/10.17352/2455-5282.000082 